\title{
Desempenho e características da carcaça de bovinos alimentados com dietas com caroço de algodão
}

\author{
[Performance and carcass traits of steers fed diets containing whole cottonseed] \\ Q.P.B. Costa $^{1}$, F.S. Wechsler ${ }^{1}$, D.P.B. Costa $^{2}$, A. Polizel Neto ${ }^{3}$, R.O. Roça ${ }^{4}$, T.P. Brito ${ }^{1}$ \\ ${ }^{1}$ Universidade Estadual Paulista - Faculdade de Medicina Veterinária e Zootecnia (UNESP/FMVZ) \\ Fazenda Experimental Lageado - Departamento de Gestão e Tecnologia Agroindustrial \\ 18603-970 - Botucatu, SP \\ ${ }^{2}$ Instituto Federal de Educação - Ciência e Tecnologia de Mato Grosso - Campo Novo do Parecis, MT \\ ${ }^{3}$ Universidade Federal de Mato Grosso - Instituto de Ciências da Saúde - Sinop, MT \\ ${ }^{4}$ Faculdade de Ciências Agronômicas - UNESP - Botucatu, SP - Pesquisador do CNPq \\ RESUMO
}

\begin{abstract}
Avaliou-se o efeito da adição de caroço de algodão à dieta de bovinos confinados sobre o desempenho animal e características da carcaça. Usaram-se 36 novilhos Nelore com médias de idade e peso vivo inicial de 20 meses e 333,5kg. Os animais foram confinados e receberam dietas com os seguintes teores de caroço de algodão: 0; 14,35\%; 27,51\%; e 34,09\% na matéria seca da dieta. O ganho de peso diário, peso vivo final e consumo de matéria seca diminuíram linearmente com o aumento da proporção de caroço de algodão na dieta. Não foi observado efeito sobre o ganho de peso total ajustado ao consumo. Os pesos da carcaça e do contrafilé diminuíram linearmente com o aumento da proporção de caroço de algodão na dieta. Não foi observado efeito do teor de caroço de algodão sobre a área de olho de lombo. A espessura de gordura de cobertura do dorso e da garupa diminuíram com o aumento do teor de caroço de algodão. Observou-se correlação de 0,62 entre as duas medidas de gordura. A adição de caroço de algodão à dieta de bovinos de corte não se mostrou vantajosa, pois diminuiu o desempenho animal e a deposição de gordura na carcaça.
\end{abstract}

Palavras-chave: novilho, área de olho de lombo, consumo, ganho de peso, gordura

\begin{abstract}
The purpose of this experiment was to evaluate the effect of adding whole cottonseed to the diet of feedlot cattle over the performance and carcass traits. Thirty six Nellore bullocks were used, with an average age of 20 months and average initial weight of $333.5 \mathrm{~kg}$. The animals were raised on feedlot and fed diets with the following content of whole cottonseed: 0 ; $14.35 \%$; 27.51\%; or $34.09 \%$ on a dry matter basis. The daily weight gain, final weight and dry matter intake decreased linearly as the proportion of cottonseed increased. No effect of cottonseed on total weight gain adjusted for intake was observed. Carcass and ribeye weights decreased linearly as cottonseed content increased. No effect of cottonseed content was observed for ribeye area. In contrast, back fat and rump fat thickness decreased as cottonseed content increased. A correlation of .62 was observed between back fat and rump fat. Adding whole cottonseed to beef cattle diets did not prove advantageous because it reduced animal performance and carcass fat deposition.
\end{abstract}

Keywords: steer, ribeye area, intake, weight gain, fat

Recebido em 17 de março de 2010

Aceito em 4 de abril de 2011

E-mail: queziapereira@yahoo.com.br

Apoio financeiro: FAPESP. 


\section{INTRODUÇÃO}

O Brasil ocupa uma posição de destaque no cenário mundial do mercado da carne bovina, porém novas alternativas devem ser buscadas para o incremento da produtividade. A base do rebanho brasileiro é constituída por raças zebuínas, com destaque para a raça Nelore, pelo seu inestimável patrimônio genético para a bovinocultura como produtora de carne e pelos bons índices de desempenho econômico (Costa et al., 2007).

A produção de ruminantes no Brasil tem como base o uso de pastagens naturais ou cultivadas, mas é conhecida a descontinuidade da produção dessas pastagens durante o ano. Além disso, o avanço da agricultura sobre as áreas de pastagens e a elevação do custo da terra fortalecem a tendência de se obter maior ganho por área. Nesse contexto, o confinamento de bovinos aparece como alternativa, pois agrega valor ao produto final por fornecer animais para o abate na entressafra, que apresentem características da carcaça desejáveis com carne de boa aparência e macia. Entretanto, os gastos com alimentação no confinamento são altos.

Na tentativa de diminuir custos com alimentação, têm-se elaborado dietas com alimentos alternativos, como os resíduos agroindustriais (Nunes et al., 2007). Entre esses, o caroço de algodão constitui uma excelente opção para uso em confinamentos, pois associa alto teor de proteína, fibra e energia (Bertrand et al., 2005).

Esse alto teor de energia, atribuído ao óleo presente nas sementes oleaginosas, constitui uma das limitações ao uso do caroço de algodão, pois o excesso de ácidos graxos insaturados pode causar alteração na fermentação ruminal, devido à supressão das atividades de bactérias celulolíticas e metanogênicas (Van Soest, 1994). A utilização de quantidades elevadas de alimentos ricos em lipídios na dieta de ruminantes pode prejudicar a digestibilidade da fibra no rúmen, comprometendo o desempenho animal (Fernandes et al., 2002). Portanto, é importante determinar qual a proporção a ser usada na dieta de bovinos de corte que não cause problemas metabólicos e digestivos, bem como avaliar o desempenho produtivo e a qualidade da carcaça produzida.

Este trabalho teve o objetivo de avaliar o efeito da adição de caroço de algodão à dieta de bovinos Nelore terminados em confinamento sobre o desempenho animal, o rendimento e as características da carcaça.

\section{MATERIAL E MÉTODOS}

$\mathrm{O}$ experimento foi realizado entre agosto e novembro de 2007. A região do experimento caracteriza-se por uma estação quente e úmida, de outubro a abril, seguida de outra fria e seca, de maio a setembro.

Usaram-se 36 bovinos da raça Nelore, machos, não castrados, que estavam em pastos de Brachiaria brizantha, suplementados com concentrado, com médias de idade de 20 meses e peso vivo de 333,5kg, no início do confinamento, que durou 94 dias. Os animais foram identificados, vacinados e submetidos a controle sanitário contra parasitas antes do período experimental.

O confinamento foi constituído por 12 baias descobertas com piso de areia. Cada baia de $120 \mathrm{~m}^{2}$ continha cocho, bebedouro e três animais a ela destinados aleatoriamente. Foram sorteadas três baias por tratamento e usaram-se quatro dietas com os seguintes teores de caroço de algodão: $0 ; 14,35 \%$; 27,51\%; e 34,09\% em relação à matéria seca (MS) (Tab. 1). As dietas foram formuladas com base nas exigências de machos não castrados em crescimento, com ganho de peso diário de $1,1 \mathrm{~kg} / \mathrm{animal} / \mathrm{dia}$ (Nutrient..., 1996), e apresentavam, aproximadamente, $60 \%$ de MS, $14 \%$ de proteína bruta (PB) e $50 \%$ de volumoso. Foram fornecidas três vezes ao dia, às seis, 13 e 17 horas, em sistema de dieta completa, permitindose sobra de aproximadamente $5 \%$.

Amostras dos ingredientes da dieta foram colhidas e posteriormente moídas em peneira com crivo de $1 \mathrm{~mm}$, para determinação do teor de MS, PB, extrato etéreo (EE), fibra em detergente neutro (FDN) e fibra em detergente ácido (FDA) segundo Nogueira e Souza (2005) (Tab. 2). 
Tabela 1. Proporção dos ingredientes das dietas com base na matéria seca e composição bromatológica

\begin{tabular}{lcccc}
\hline \multirow{2}{*}{ Ingrediente (\%) } & \multicolumn{4}{c}{ Caroço de algodão (\%) } \\
\cline { 2 - 4 } & 0 & 14,35 & 27,51 & 34,09 \\
\hline Cana-de-açúcar & 50,00 & 50,00 & 50,00 & 50,00 \\
Caroço de algodão & 0,00 & 14,35 & 27,51 & 34,09 \\
Grão de milho triturado & 28,13 & 18,68 & 10,19 & 6,01 \\
Farelo de soja & 19,47 & 14,57 & 9,90 & 7,50 \\
Ureia & 1,20 & 1,20 & 1,20 & 1,20 \\
Mistura mineral * & 0,84 & 0,84 & 0,84 & 0,84 \\
NaCl & 0,36 & 0,36 & 0,36 & 0,36 \\
Proteína bruta & 14,11 & 14,17 & 14,16 & 14,13 \\
Extrato etéreo & 2,99 & 4,98 & 6,81 & 7,73 \\
Fibra em detergente neutro & 35,17 & 39,63 & 43,70 & 45,73 \\
Fibra em detergente ácido & 23,33 & 26,33 & 29,06 & 30,42 \\
Nutrientes digestíveis totais ${ }^{(1)}$ & 71,76 & 71,27 & 70,84 & 70,63 \\
\hline
\end{tabular}

*Composição/kg: P= 136,80g; Ca= 205,00g; Mg= 11,00g; S= 21,23g; Zn= 10,50g; Cu= 3,75g; $\mathrm{Mn}=1,50 \mathrm{~g}$; $\mathrm{Fe}=$ 4,50g; $\mathrm{Co}=0,20 \mathrm{~g}$; I= 0,30g e Se= 28,82mg. ${ }^{(1)}$ Estimado pela composição dos alimentos segundo Valadares Filho et al. (2006).

Tabela 2. Análise bromatológica dos ingredientes das dietas oferecidas a novilhos

\begin{tabular}{lcccccc}
\hline \multirow{2}{*}{ Ingrediente } & MS & PB & EE & MM & FDN & FDA \\
\cline { 3 - 7 } & $\%$ & & & $\%$ MS & & \\
\hline Caroço de algodão & 92,89 & 22,42 & 19,35 & 3,18 & 44,65 & 29,37 \\
Grão de milho triturado & 89,28 & 8,14 & 6,79 & 1,88 & 10,37 & 5,44 \\
Farelo de soja & 89,67 & 48,69 & 2,93 & 6,34 & 19,83 & 14,36 \\
Cana-de-açúcar & 28,95 & 2,31 & 1,01 & 2,39 & 56,79 & 38,02 \\
\hline
\end{tabular}

MS = matéria seca, PB = proteína bruta, EE = extrato etéreo, MM = matéria mineral, FDN = fibra em detergente neutro e FDA = fibra em detergente ácido.

Uma vez ao mês, durante cinco dias consecutivos, as sobras presentes nos cochos foram pesadas e colhidas para se determinar o teor e o consumo de MS para cada tratamento. Durante o período experimental, foram realizadas pesagens dos animais, duas vezes ao mês, sempre após oito horas de jejum de sólidos, para monitoração do ganho de peso diário.

A área de olho de lombo (AOL) e a espessura de gordura de cobertura do dorso (EGC) e da garupa (P8) foram medidas por ultrassonografia nos dias oito e 90 do período experimental. Para medir a AOL e a EGC, foram tomadas imagens entre a $12^{\mathrm{a}}$ e a $13^{\mathrm{a}}$ costela, transversalmente ao músculo longíssimo dorsal, sendo a EGC medida no terço médio distal da AOL. Para a mensuração de P8, foram tomadas as imagens na junção entre 0 músculo glúteo médio e o bíceps femoral. Todas as imagens foram tomadas do lado direito, após limpeza da pele e aplicação de óleo vegetal como acoplante acústico. Usou-se um aparelho PIEMEDICAL - Scanner 200, com uma sonda linear de $18 \mathrm{~cm}$ e $3,5 \mathrm{MHz}$.
Os animais foram pesados, após oito horas de jejum de sólidos, aos 93 dias de confinamento. Dois dias depois, foram abatidos, após jejum de sólidos de 24 horas, em frigorífico comercial, a $345 \mathrm{~km}$ do local do experimento, no fluxo normal de abate. As carcaças, divididas em duas metades longitudinais, foram pesadas para obtenção do peso da carcaça quente. De cada meia-carcaça esquerda, resfriada a $7^{\circ} \mathrm{C}$ por 24 horas, foi retirado o contrafilé, na altura da $12^{\mathrm{a}}$ vértebra torácica e terceira vértebra lombar. Os contrafilés, embalados em sacos plásticos, identificados, acondicionados em caixas frigoríficas e congelados a $-18^{\circ} \mathrm{C}$, permaneceram sob essa temperatura por 35 dias, quando foram pesados, congelados.

O experimento obedeceu a um delineamento inteiramente ao acaso, com quatro tratamentos e três repetições, sendo a média de cada baia a unidade experimental. Para o peso vivo, consumo, gordura de cobertura e AOL, adotou-se um modelo com medidas repetidas: Y $i j \kappa=\mu+\mathrm{T} i$ $+\epsilon i j+\mathrm{M} \kappa+(\mathrm{TM}) i \kappa+\Delta i j \kappa$, em que: Yijk é o 
valor observado na $\kappa$-ésima medida da $j$-ésima unidade experimental (baia), que recebeu o $i$ ésimo tratamento; $\mu$ é a média geral; Ti é o efeito fixo do i-ésimo tratamentoc $i j$ é o efeito aleatório do erro experimental referente às unidades experimentais (baias); $\mathrm{M} \kappa$ é o efeito fixo da $\kappa$-ésima medida; (TM) $i \kappa$ é o efeito fixo da interação entre o $i$-ésimo tratamento e a $\kappa$ ésima medida, e $\Delta i j \kappa$ é o efeito aleatório do erro experimental referente às medidas. Para peso da carcaça quente e do contrafilé, o modelo adotado foi: $\mathrm{Y} i j \kappa=\mu+\mathrm{T} i+\mathrm{Cij}$. Os efeitos de tratamentos foram desdobrados mediante regressão polinomial (peso vivo, consumo, peso da carcaça e do contrafilé e AOL) ou logarítmica (gordura de cobertura).
Analisou-se também a correlação entre a EGC e a P8, no início e fim do período experimental. Com este fim, aplicou-se o segundo modelo acima, para cada época, e calculou-se a correlação residual entre estas variáveis. Para as análises estatísticas, usaram-se os programas do SAS (2001).

\section{RESULTADOS E DISCUSSÃO}

O ganho de peso diário, o peso vivo final e o consumo de MS diário diminuíram linearmente com o aumento da proporção de caroço de algodão na dieta (Tab. 3).

Tabela 3. Médias e respectivos erros-padrão (EP) das características de desempenho de novilhos, segundo as dietas

\begin{tabular}{lccccccc}
\hline \multirow{2}{*}{ Característica } & \multicolumn{5}{c}{ Caroço de algodão (\%) } & \multirow{2}{*}{ EP } & \multirow{2}{*}{$\mathrm{P}^{(1)}$} \\
\cline { 2 - 6 } & 0 & 14,35 & 27,51 & 34,09 & & \\
\hline Peso vivo inicial (kg) & 335 & 331 & 334 & 334 & 7,38 & $>0,10$ \\
Peso vivo final (kg) & 462 & 447 & 442 & 435 & 7,38 & $<0,05$ \\
Ganho de peso diário (kg/animal) & 1,35 & 1,24 & 1,17 & 1,09 & 0,07 & $<0,01$ \\
Consumo de matéria seca (kg/animal) & 12,54 & 11,58 & 11,16 & 10,10 & 0,31 & $<0,01$ \\
Ganho total de peso (kg/animal) ${ }^{(2)}$ & 113,9 & 113,6 & 110,7 & 114,3 & - & $>0,10$ \\
Conversão alimentar ${ }^{(3)}$ & 9,2 & 9,3 & 9,6 & 9,4 & - & - \\
\hline
\end{tabular}

${ }^{(1)}$ Probabilidade de erro do tipo 1 para o efeito linear de nível de caroço de algodão. ${ }^{(2)}$ Usando-se o consumo de matéria seca como covariável. Os erros-padrão são, respectivamente,: 6,47; 4,08; 4,03 e 6,64. ${ }^{(3)}$ Apresentada como informação suplementar; a análise estatística usada é a do ganho total de peso ajustado para o consumo de matéria seca.

A diminuição de consumo observada no presente trabalho pode estar associada ao aumento do teor de EE na dieta. Em ruminantes, dietas com teores de lipídios maiores que $7 \%$ da MS podem ter a degradação do alimento prejudicada (Valinote et al., 2006). Para Moore et al. (1986), dietas com mais de $4 \%$ de gordura proporcionam diminuição da digestão da fibra em novilhos. No presente trabalho, as dietas com caroço de algodão apresentaram valores de EE acima dos $4 \%$ da MS.

O excesso de ácidos graxos insaturados pode causar alteração na fermentação ruminal, devido à supressão das atividades de bactérias celulolíticas e metanogênicas (Van Soest, 1994). Essa gordura também adere à partícula do alimento e cria uma barreira física à ação de microrganismos e de enzimas microbianas (Sullivan et al., 2004).
Allen (2000) afirmou que o consumo de MS depende das características da fonte ou das fontes de fibra da dieta como: tamanho de partícula, digestibilidade e taxa de passagem para o retículo, que afetam positiva ou negativamente a ingestão de MS. O aumento da concentração de FDN e FDA nas rações pode ocasionar diminuição da degradabilidade ruminal da matéria orgânica e da digestibilidade desta no trato digestivo total. Um maior acúmulo de material não digestível no rúmen acentua o efeito de enchimento, provocando menor consumo de MS (Pires et al., 2008). No presente trabalho, o caroço de algodão foi usado em substituição ao farelo de soja e ao grão de milho triturado. Portanto, ao se aumentar o teor de caroço de algodão na dieta, também se aumentou o teor de FDN e FDA (Tab. 1), o que pode ter acarretado diminuição do consumo de MS e do ganho de peso. 
Não foi observado efeito sobre o ganho de peso total ajustado ao consumo de MS como covariável (Tab. 3). Esse ganho ajustado representa a eficiência de transformação da dieta em peso vivo, ou seja, a conversão alimentar. Prado et al. (1995), Huerta-Leidenz et al. (1991), Aferri et al. (2005) e Jorge et al. (2009) não constataram diferença para conversão alimentar com a adição de caroço de algodão à dieta, enquanto Pesce (2008) observou menor eficiência alimentar do tratamento sem caroço de algodão do que os tratamentos com caroço de algodão. O ganho de peso total ajustado não sofreu influência da adição de caroço de algodão, provavelmente porque a diminuição do ganho de peso diário acompanhou o menor consumo de MS, que deve ter sido influenciado tanto pelo valor energético da dieta quanto pela quantidade de fibra.

Os pesos da carcaça quente (PCQ) e do contrafilé diminuíram linearmente com o aumento da proporção de caroço de algodão na dieta. Suas equações de regressão foram: $Y_{\mathrm{PCQ}}=247,094$ 0,576.X e $Y_{\text {contrafilé }}=4,637$ - 0,016.X, respectivamente (Tab. 4). No entanto, o peso da carcaça quente e o peso do contrafilé, ajustados para a covariável peso vivo final, não sofreram influência da proporção de caroço de algodão $(\mathrm{P}>0,05)$, o que sugere que a inclusão do caroço de algodão não altera o desenvolvimento alométrico da carcaça ou do contrafilé. O peso da carcaça quente ajustado para a covariável peso vivo final representou o rendimento de carcaça quente.

Não foi observado efeito do caroço de algodão sobre a AOL (Tab. 4). Já a EGC e a P8 diminuíram com o aumento da proporção de caroço de algodão na dieta (Fig. 1). Esse efeito persistiu $(\mathrm{P}<0,05)$, mesmo quando se incluiu na regressão a covariável peso vivo final, o que sugere ação negativa do caroço de algodão sobre a deposição de gordura. Observou-se correlação de $0,62(\mathrm{P}<0,01)$ entre P8 e EGC. Sabe-se que a deposição de gordura na garupa ocorre mais precocemente que nas costelas (Yokoo et al., 2008); por esse motivo, a área da garupa é local indicado para se verificar as reservas corporais prontamente disponíveis (Maciel, 2006).

Aferri et al. (2005) observaram que a inclusão de $21 \%$ de caroço de algodão na dieta não influenciou o peso e o rendimento de carcaça, a AOL e a EGC, obtidas por ultrassom. O mesmo fato foi observado por Pesce (2008) em relação a essas variáveis, como também em relação à P8. Jorge et al. (2009) tampouco observaram efeito sobre o rendimento de carcaça, EGC e AOL, enquanto Huerta-Leidenz et al. (1991) obtiveram redução da AOL e do peso da carcaça ajustada ao peso vivo inicial. Contudo, não houve diferença para EGC com a adição de caroço de algodão. A AOL e a EGC podem estar associadas ao peso da carcaça quente (Costa et al., 2007). Segundo Luchiari Filho (2000), à medida que aumenta a AOL, aumenta a proporção da carcaça e viceversa. No entanto, no presente trabalho, apesar de o peso da carcaça quente e do contrafilé terem diminuído com o aumento da adição de caroço de algodão na dieta, a AOL não diminuiu.

Neste trabalho, os bovinos apresentaram medidas acima de $5 \mathrm{~mm}$ para EGC e P8, mesmo quando diminuíram esses valores com a adição de caroço de algodão na dieta. Portanto, os animais apresentavam bom acabamento da carcaça, já que a EGC deve se situar entre 5 e $7 \mathrm{~mm}$ (Luchiari Filho, 2000).

Tabela 4. Médias e respectivos erros-padrão (EP) das características da carcaça de novilhos, segundo as dietas

\begin{tabular}{lccccccc}
\hline \multirow{2}{*}{ Característica } & \multicolumn{4}{c}{ Caroço de algodão (\%) } & \multirow{2}{*}{ EP } & \multirow{2}{*}{$\mathrm{P}^{(1)}$} \\
\cline { 2 - 5 } & 0 & 14,35 & 27,51 & 34,09 & & \\
\hline Carcaça quente (kg/animal) & 248 & 237 & 233 & 227 & 6,44 & $<0,05$ \\
Contrafilé (kg/animal) & 4,71 & 4,30 & 4,13 & 4,17 & 0,15 & $<0,05$ \\
Rendimento médio de carcaça $(\%)^{(2)}$ & 55,60 & 52,98 & 55,71 & 52,16 & - & - \\
Área final de olho de lombo $\left(\mathrm{cm}^{2}\right)$ & 70,94 & 68,58 & 66,72 & 68,54 & 2,15 & $>0,10$ \\
Gordura de cobertura do dorso (mm) & 6,44 & 5,33 & 5,00 & 5,17 & 0,23 & $<0,01$ \\
Gordura de cobertura da garupa (mm) & 7,00 & 6,11 & 5,33 & 5,33 & 0,32 & $<0,01$ \\
\hline
\end{tabular}

${ }^{(1)}$ Probabilidade de erro do tipo 1 para o efeito linear de nível de caroço de algodão. ${ }^{(2)}$ Apresentado como informação suplementar; a análise estatística usada é a do peso da carcaça ajustado para peso vivo final. 


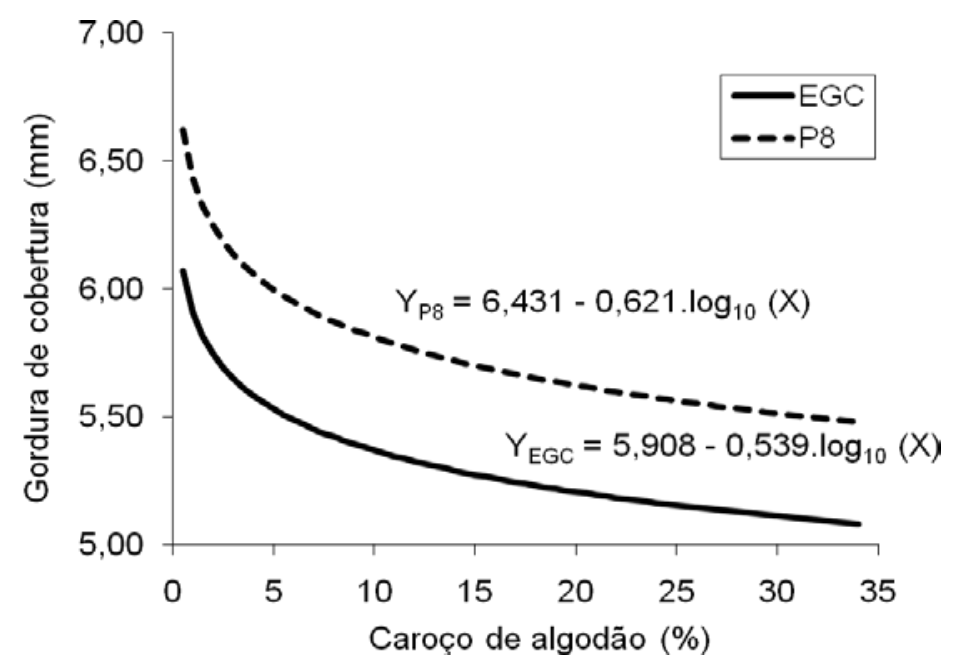

Figura 1. Espessura de gordura de cobertura do dorso (EGC) e da garupa (P8) de novilhos obtida por ultrassom em função da quantidade de caroço de algodão.

Segundo Page et al. (1997), em estudo com bovinos Brangus alimentados com 30\% de caroço de algodão, o aumento na EGC sem aumento na AOL demonstra que a adição de caroço de algodão aumenta a deposição de gordura, pois a EGC reflete a porcentagem de gordura da carcaça (Rodrigues et al., 2001). No presente trabalho, ocorreu o contrário, já que a adição de caroço de algodão diminuiu a deposição de gordura na EGC e na P8, sem alterar a AOL. Contudo, sabe-se que a composição da carcaça referente à proporção de músculo, gordura e osso é influenciada pela idade, peso, raça, nutrição, entre outros fatores (Berg e Butterfield, 1968).

\section{CONCLUSÕES}

A adição de caroço de algodão na dieta de bovinos de corte não se mostrou biologicamente vantajosa, pois o caroço de algodão, em substituição ao farelo de soja e ao grão de milho triturado na dieta, diminuiu o desempenho animal e a deposição de gordura da carcaça de bovinos Nelore. Entretanto, esse suplemento pode mostrar-se economicamente vantajoso se o seu custo for baixo, pois a conversão alimentar não foi influenciada pela sua adição à dieta.

\section{AGRADECIMENTOS}

À Fazenda Mateirinha, pelo auxílio fundamental para a execução desse experimento, e à Fapesp, pelo auxílio financeiro.

\section{REFERÊNCIAS BIBLIOGRÁFICAS}

AFERRI, G.; LEME, P.R.; SILVA, S.L. et al. Desempenho e características de carcaça de novilhos alimentados com dietas contendo diferentes fontes de lipídios. Rev. Bras. Zootec., v.34, p.1651-1658, 2005.

ALLEN, M. S. Effects of diet on short-term regulation of feed intake by lactating dairy cattle. J. Dairy Sci., v.83, p.1598-1624, 2000.

BERG, R. T.; BUTTERFIELD, R. M. Growth patterns of bovine muscle, fat and bone. J. Anim. Sci., v.27, p.611-619, 1968.

BERTRAND, J. A.; SUDDUTH, T. Q.; CONDON, A. et al. Nutrient content of whole cottonseed. J. Dairy Sci., v.88, p.1470-1477, 2005.

COSTA, D.P.B.; ABREU, J.B.R.; MOURÃO, R.C. et al. Características de carcaça de novilhos inteiros Nelore e F1 Nelore x Holandês. Cienc. Anim. Bras., v.8, p.687-696, 2007.

FERNANDES, J.J.R.; PIRES, A.V.; SANTOS, F.A.P. et al. Teores de caroço de algodão em dietas contendo silagem de milho para vacas em lactação. Acta Scient., v.24, p.1071-1077, 2002.

HUERTA-LEIDENZ, N.O.; CROSS, H.R.; LUNT, D.K. et al. Growth, carcass traits, and fatty acid profiles of adipose tissues from steers fed whole cottonseed. J. Anim. Sci., v.69, p.36653672, 1991. 
JORGE, J.R.V.; ZEOULA, L.M.; PRADO, I.N. et al. Gordura protegida sobre o desempenho, carcaça e composição química da carne de novilhos Holandês. Arch. Zootec., v.58, p.371382, 2009

LUCHIARI FILHO, A. Pecuária da carne bovina. São Paulo: Albino Luchiari Filho, 2000. 134p.

MACIEL, A. B. B. Proposta de avaliação da condição corporal em vacas Holandesas e Nelores. 2006. 59f. Dissertação (Mestrado em Zootecnia) - Faculdade de Medicina Veterinária e Zootecnia, Universidade Estadual Paulista, Botucatu, SP.

MOORE, J.A.; SWINGLE, R.S.; HAL, W.H. Effects of whole cottonseed, cottonseed oil or animal fat on digestibility of wheat straw diets by steers. J. Anim. Sci., v.63, p.1267-1273, 1986.

NUTRIENT requirements of beef cattle. 7.ed. Washington, DC: National Academy of Sciences, 1996. 244p.

NOGUEIRA, A.R.A.; SOUZA, G.B. Manual de laboratórios: solo, água, nutrição vegetal, nutrição animal e alimentos. São Carlos: Embrapa Pecuária Sudeste, 2005. 313p.

NUNES, H.; ZANINE, A.M.; MACHADO, T.M.M. et al. Alimentos alternativos na dieta dos ovinos: uma revisão. Arch. Latinoam. Prod. Anim., v.15, p.147-158, 2007.

PAGE, A.M.; STURDIVANT, C.A.; LUNT, D.K. et al. Dietary whole cottonseed depresses lipogenesis but has no effect on stearoyl coenzyme desaturase activity in bovine subcutaneous adipose tissue. Comp. Biochem. Physiol., Part B: Biochem. Mol. Biol., v.118, p.79-84, 1997.

PESCE, D.M.C. Efeito da dieta contendo caroço de algodão no desempenho, características quantitativas da carcaça e qualitativas da carne de novilhos Nelore confinados. 2008. 155f. Tese (Doutorado em Zootecnia) - Faculdade de Zootecnia e Engenharia de Alimentos, Universidade de São Paulo, Pirassununga, SP.
PIRES, A.V.; SUSIN, I.; SIMAS, J.M.C. et al. Substituição de silagem de milho por cana-deaçúcar e caroço de algodão nos parâmetros ruminais, síntese de proteína microbiana e utilização dos nutrientes em vacas lactantes. Cienc. Anim. Bras., v.9, p.50-58, 2008.

PRADO, I.N.; BRANCO, A.F.; ZEOULA, L.M. et al. Desempenho e características de carcaça de bovinos Nelore confinados, recebendo 15 ou $30 \%$ de caroço integral de algodão, bagaço autohidrolisado de cana-de-açúcar ou capim-elefante. Arq. Biol. Tecnol., v.38, p.353-365, 1995.

RODRIGUES, V.C.; ANDRADE, I.F.; SOUSA, J.C.D. et al. Avaliação da composição corporal de bubalinos e bovinos através do ultrassom. Cienc. Agrotecnol., v.25, p.1174-1184, 2001.

SULLIVAN, H.M.; BERNARD, J.K.; AMOS, H.E. et al. Performance of lactating dairy cows fed whole cottonseed with elevated concentrations of free fatty acids in the oil. $J$. Dairy Sci., v.87, p.665-671, 2004.

VALADARES FILHO, S.C.; MAGALHÃES, K.A.; ROCHA JÚNIOR, V.R. et al. Tabelas brasileiras de composição de alimentos para bovinos. 2.ed. Viçosa: UFV, 2006. 329p.

VALINOTE, A.C.; NOGUEIRA FILHO, J.C.M.; LEME, P.R. et al. Fontes de lipídio e monensina sódica na fermentação, cinética e degradabilidade ruminal de bovinos. Pesq. Agropecu. Bras., v.41, p.117-124, 2006.

VAN SOEST, P.J. Nutritional ecology of the ruminant. 2.ed. Ithaca: Cornell University, 1994. 528p.

YOKOO, M.J.; ALBUQUERQUE, L.G.; LÔBO, R.B. et al. Genetic and environmental factors affecting ultrasound measures of longissimus muscle area and backfat thickness in Nelore cattle. Liv. Sci., v.117, p.147-154, 2008. 